\title{
Lateral Cephalometric Norms for Adolescent Kuwaitis: Hard Tissue Measurements
}

\author{
Badreia Al-Jame $^{\mathrm{a}}$ Jon Årtun ${ }^{\mathrm{b}}$ Rashed Al-Azemi ${ }^{\mathrm{c}}$ Faraj Behbehani ${ }^{\mathrm{b}}$ \\ Sana BuHamra ${ }^{\text {d }}$ \\ ${ }^{a}$ Private Practice, Northern Nuqra Medical Complex; ${ }^{b}$ Department of Developmental and Preventive Sciences, \\ Faculty of Dentistry, Kuwait University; ${ }^{\mathrm{c} B n e i d}$ Al-Gar Dental Center, Ministry of Health, and \\ ${ }^{\mathrm{d}}$ Department of Statistics, Faculty of Science, Kuwait University, Kuwait
}

\section{Key Words}

Lateral cephalograms · Cephalometric norms ·

Kuwaitis, adolescent $\cdot$ Treatment planning

\begin{abstract}
Objective: The purpose of this study was to establish lateral cephalometric hard tissue norms for adolescent Kuwaitis and to compare them with published norms.

Subjects and Methods: Digital lateral cephalograms were made of 162 Kuwaitis ( 82 boys and 80 girls of mean age $13.27 \pm 0.42$ years and $13.21 \pm 0.43$ years, respectively), with almost ideal occlusion. Anatomic landmarks were identified directly on the digital images. Linear and angular measurements were calculated electronically using the Dolphin version 9 software package. Results: The average subject in the sample had a steeper mandibular plane, a more convex profile with a tendency for reduced chin protrusion, and a more protrusive dentition than the norms of the common analysis systems. In addition, the ranges of the skeletal and dentoalveolar parameters were larger than those reported in the abovementioned norms. Gender differences were limited to maxillary and mandibular length and lower anterior fa-
\end{abstract}

cial height. Conclusion: The present findings indicate that Kuwaiti norms for incisor inclination and protrusion should be used as a reference when making the extraction decision in Kuwaiti orthodontic patients, and that the variation in skeletal relationships among subjects with satisfactory occlusal compensations is larger than previously documented, suggesting a need for establishing different norms for different skeletal patterns.

Copyright $(2006$ S. Karger AG, Basel

\section{Introduction}

The need for lateral cephalometric analysis in orthodontic diagnosis and treatment planning is well established. The principle is that the radiographic measurements of each patient are compared with normative values. Small differences between the patient's measurements and the respective norms are interpreted as a normal variation, while larger differences indicate structural deviations. A systematic comparison of the actual and normative values of each measurement allows the practitioner to determine whether the malocclusion in question is due merely to deviations in position of the teeth

\section{KARGER}

Fax +4161306 1234 E-Mail karger@karger.ch www.karger.com 
and the alveolar processes or whether discrepancies exist in size and position of the jaws. The analyses will indicate necessary structural changes for achieving optimal morphologic results and will support the extraction decision as well as the decision whether or not to perform orthognathic surgery as part of the treatment.

Proposed norms must reflect means and acceptable ranges of measurements collected from a representative group of subjects to be valid as standards for comparison. Due to the morphologic changes associated with growth and development $[1,2]$ the subjects must be of relevant age, and any gender differences should be explored. Moreover, the samples should be limited to subjects with close to ideal occlusion to avoid bias due to effect of the differences in skeletal and dentoalveolar morphology among subjects with different types of malocclusion [3-5]. Finally, the samples must be large enough to be representative of the population.

The norms of the common lateral cephalometric analysis systems allow inferences only to white Americans [6-14] or Europeans [15]. Several studies comparing cephalometric measurements from samples of different ethnic origin to the published norms [16-24] as well as to comparable groups of various nationalities [25-31] have been able to demonstrate ethnic differences of clinical significance, particularly in dentoalveolar parameters. Among the few cephalometric evaluations of Arabs [24, $26,28]$ one was limited to a convenience sample of 48 adult Saudis without clearly defined occlusal criteria [26]. Although the other two studies examined 65 adolescent Jordanians [24] and 90 adolescent Egyptians [28], the inclusion criteria may not have been sufficient in limiting the samples to subjects with almost ideal occlusion, and the measures to ensure they were a representative group were not clearly stated.

The first settlers of Kuwait were Arabs from the Najd area of central Arabia [32, 33]. Other early settlers included subjects of Persian origin as well as Arabs from various neighboring areas $[32,33]$. The immigration increased dramatically concomitant with the expansion of the oil industry before and after World War II. Education and trade during the following economic boom also resulted in immigration from East Africa, Asia, Europe, and the USA through marriage to Kuwaitis [32, 33]. Cephalometric information on this racial mix is limited to an examination of adolescent orthodontic patients with deep bite and open bite malocclusions [34]. The purpose of our study was to perform a lateral cephalometric evaluation of a large, representative group of 13- to 14year-old Kuwaitis with close to ideal occlusion to estab- lish cephalometric norms for adolescent Kuwaiti orthodontic patients, and to make a clinical comparison between these norms and those of the common analysis systems.

\section{Subjects and Methods}

Subjects

Following approval by the Ethics Committee, Faculty of Dentistry, Kuwait University and authorization by the Research Department of the Kuwaiti Ministry of Education, 13- to 14-year-old 8th-grade Kuwaiti students were screened during regular school hours. The students were informed about their rights to participate in the study, and each school principal provided a well-lit room for examination. The inclusion criteria for the lateral cephalometric examination were: no history of orthodontic treatment and almost ideal occlusion, defined as perfect intercuspation and posterior tooth alignment with no transverse discrepancies, no detectable lateral shift, anterior shift less than $2 \mathrm{~mm}$, no midline deviation, positive overjet less than $3.5 \mathrm{~mm}$, positive overbite less than $2 / 3$ overlap of the maxillary to the mandibular incisors, arch length excess less than $2 \mathrm{~mm}$ in either arch, and anterior tooth irregularity less than $3.5 \mathrm{~mm}$ in either arch. Following written parental consent, 82 boys of mean age $13.27 \pm 0.42$ years and 80 girls of mean age $13.21 \pm 0.43$ years were examined.

\section{Lateral Cephalograms}

Digital lateral cephalograms were made with the teeth in centric occlusion at a focus/object distance of $150 \mathrm{~cm}$ and an object/receptor distance of $20 \mathrm{~cm}$ using a Planmeca Publication 688169 version 5 Cephalostat (Planmeca OY, Helsinki, Finland). The subjects were placed in a headholder and asked to look straight forward before adjusting the nasal positioner with built-in millimeter scale.

\section{Measurements on Lateral Cephalograms}

Anatomic landmarks as well as the 0 and $2 \mathrm{~cm}$ markings on the ruler were identified directly on the digital computer images (fig. 1). Linear and angular measurements were calculated electronically using the Dolphin version 9 software package (Dolphin Imaging and Management Solutions, Chatsworth, Calif., USA), adjusting linear readings to the actual subject dimensions.

\section{Error of the Method}

The reproducibility of the measurements was assessed by statistically analyzing the differences between double measurements taken at least 1 week apart on 20 randomly selected cephalograms. The error was calculated from the equation:

$$
\mathrm{S}_{\mathrm{x}}=\sqrt{\frac{\sum \mathrm{D}^{2}}{2 \mathrm{~N}}}
$$

where $\mathrm{D}$ is the difference between duplicated measurements and $\mathrm{N}$ is the number of double measurements [35]. The errors ranged from 0.27 (U1/APg) to 1.44 (Wits) for the linear measurements and from 0.40 (ANB) to 1.51 (U1/L1) for the angular measurements. Pearson's R between corresponding first and second measurements were all $>0.92(\mathrm{p}<0.001)$. 


\section{Data Analyses}

Descriptive statistics were performed, and Student's t tests were employed to test for gender differences. Bonferroni corrections were carried out to reduce the possibility of significances due to chance, considering $\mathrm{p}$ values less than the corresponding Bonferroni correction values as significant [36]. Sample means, standard deviations and ranges of each respective linear and angular measurement were interpreted as lateral cephalometric norms for adolescent Kuwaitis. Separate norms were calculated for boys and girls regarding parameters demonstrating gender differences. Pairwise comparisons were made between the Kuwaiti and previously published norms [6-14] (tables 1, 2), following multiplying McNamara's [13] linear skeletal norms for adolescents by 0.92 to adjust for the $8 \%$ magnification. No magnification adjustments were made to the norms for the skeletal distances Pg-NB and 'Wits' appraisal, or to the norms for the dental distances U1-APg, U1-NA, L1-NB and $\mathrm{L} 1-\mathrm{APg}$ (table 1). A difference of 2 degrees or $2 \mathrm{~mm}$ was considered clinically significant.

\section{Results}

\section{Skeletal Norms}

The only anteroposterior differences of clinical significance were the angle NA/APg, which was larger, and the linear dimensions $\mathrm{Co}-\mathrm{A}$ and $\mathrm{Co}-\mathrm{Gn}$, which were shorter than the published norms (tables 1,2). Regarding vertical parameters the increase of angle MP/FH was considered clinically significant while the increase of angle MP/SN only approached clinical significance (table 1). The linear dimension ANS-Me was similar to the common norms for adolescents (table 2). The increased ranges of the anteroposterior and vertical parameters relative to the respective ranges available in the analysis systems (table 1) were considered clinically significant.

\section{Dentoalveolar Norms}

With the exception of the distance U1-NA, all angular and linear measurements related to $\mathrm{U} 1$ and $\mathrm{L} 1$ were clinically larger in our sample (table 1) than previously submitted norms. In addition, the ranges were clinically larger than the respective ranges available in the analysis systems (table 1).

\section{Gender Differences}

Following Bonferroni correction, gender differences were only detected in the linear dimensions $\mathrm{Co}-\mathrm{A}, \mathrm{Co}-$ $\mathrm{Gn}$, and ANS-Me, with boys having 4.18, 4.18, and $3.38 \mathrm{~mm}$ larger average values, respectively $(\mathrm{p}<0.001$, table 2).

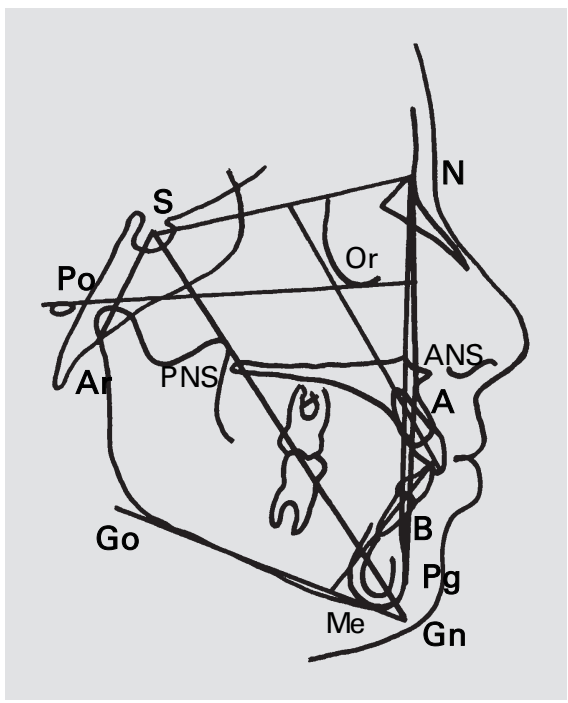

Fig. 1. Cephalometric tracing of average subject in the sample, indicating identification of landmarks and reference lines. $\mathrm{S}=$ Center of pituitary fossa of sphenoid bone; $\mathrm{N}=$ intersection of internasal suture with nasal frontal suture in midsagittal plane; ANS = tip of anterior nasal spine; $\mathrm{A}=$ deepest point of curve of maxilla between anterior nasal spine and dental alveolus; $\mathrm{B}=$ most posterior point in concavity along anterior border of symphysis; $\mathrm{Pg}=$ most anterior point on midsagittal symphysis; $\mathrm{Gn}=$ midpoint between most anterior and inferior point on bony chin; $\mathrm{Me}=$ most inferior point of symphysis; Go = most convex point along inferior border of ramus; $\mathrm{Ar}=$ posterior border of neck of condyle; Po = highest point of ear canal, most superior point of external auditory meatus; Or = most inferior point of external border of orbital cavity; PNS = tip of posterior nasal spine.

\section{Discussion}

We applied stratified cluster sampling methods [37] when determining school classes from which students should be screened, defining the students in the public schools of each of the 6 administrative areas in Kuwait as 6 different strata and the students in the different private schools as the 7th stratum. Despite efforts at achieving population proportions among the subjects with almost ideal occlusion, subjects from Ahmadi, Jahra and the private schools were underrepresented in our sample due to lack of compliance. However, no differences were detected in skeletal and dentoalveolar parameters among the subjects from the different areas. The present sample may therefore allow valid inferences to adolescent $\mathrm{Ku}$ waitis with almost ideal occlusion.

Lack of samples of similar representation from different ethnic groups precluded the use of statistical analyses for testing of ethnic differences. Besides, such studies may 
Table 1. Means, standard deviations (SD) and ranges (minimum, maximum) of lateral cephalometric parameters with no significant gender differences of 82 Kuwaiti boys and 80 Kuwaiti girls with almost ideal occlusion (Kuwaiti norms), and similar parameters from the respective original articles (published norms) on the common lateral cephalometric analysis systems (references)

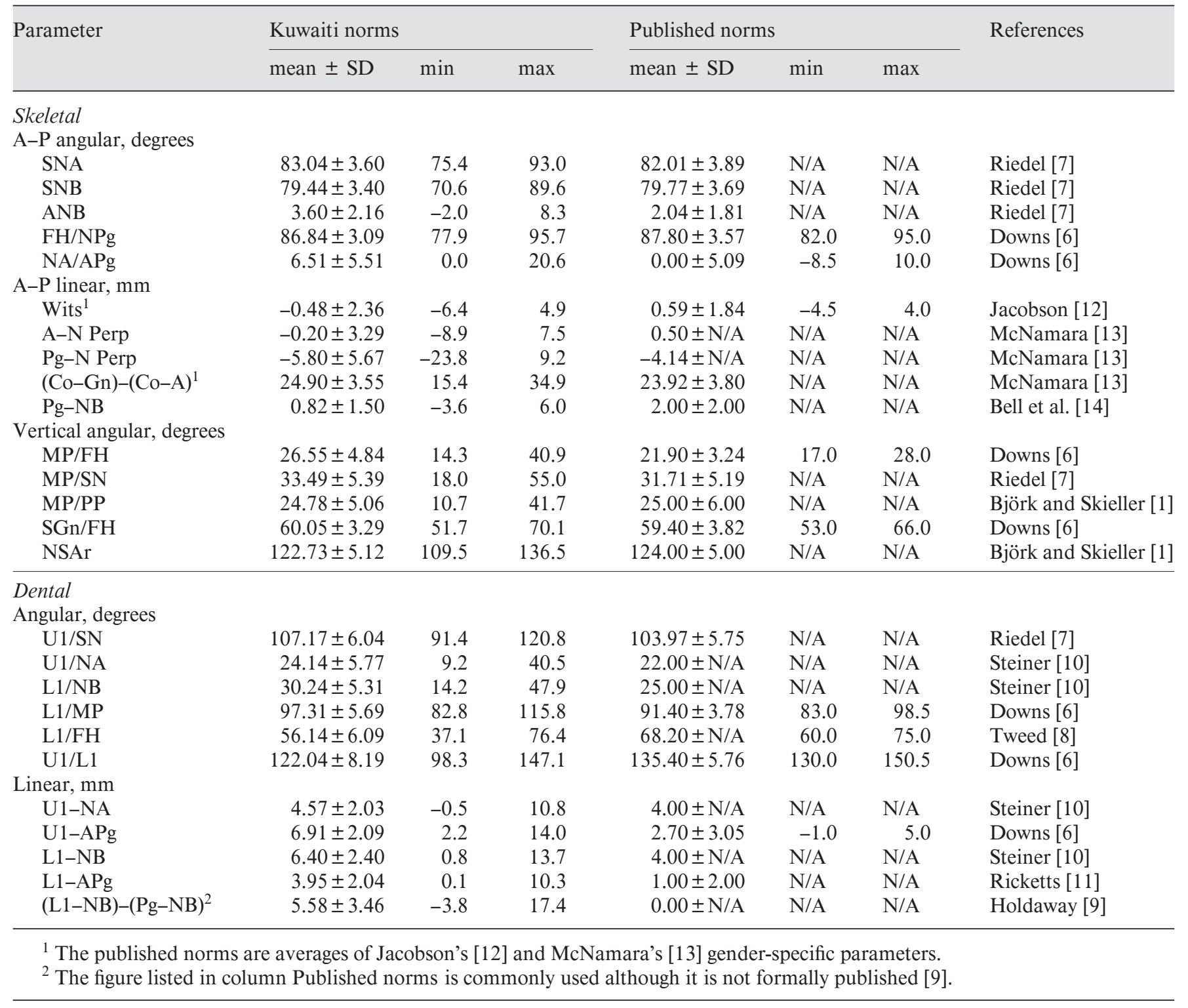

be considered to be of minor clinical significance. Our purpose was to establish valid cephalometric norms for adolescent Kuwaitis at ages when optimal one-phase comprehensive orthodontic treatment normally commences, and to confirm our hypothesis that such norms are needed for appropriate clinical decision-making. We therefore considered mean values that differed by at least $2 \mathrm{~mm}$ or 2 degrees to be large enough to justify the use of population-specific norms for Kuwaitis rather than com- paring to the previously published norms. We decided to use actual rather than relative differences when determining clinical significance, since a 1-degree increase in angles SNA and U1/SN for mathematical reasons will be associated with a similar increase in angles ANB and U1/ NA, despite the large difference in mean values of angles SNA vs. ANB and angles U1/SN vs. U1/NA. The fact that we did not adjust the linear norms of Downs [6], Steiner [10] and Ricketts [11] for magnification will have contrib- 
Table 2. Means, standard deviations (SD) and ranges (minimum, maximum) of lateral cephalometric parameters with significant gender differences $(\mathrm{p}<0.001)$ of 82 Kuwaiti boys and 80 Kuwaiti girls with almost ideal occlusion (Kuwaiti norms), and similar parameters from the respective original articles (published norms) on the common lateral cephalometric analysis systems (references)

\begin{tabular}{|c|c|c|c|c|c|c|c|}
\hline \multirow[t]{2}{*}{ Parameter } & \multicolumn{3}{|l|}{ Kuwaiti norms } & \multicolumn{3}{|c|}{ Published norms } & \multirow[t]{2}{*}{ Reference } \\
\hline & mean $\pm \mathrm{SD}$ & $\min$ & $\max$ & mean $\pm \mathrm{SD}$ & $\min$ & $\max$ & \\
\hline \multicolumn{8}{|l|}{ Skeletal } \\
\hline \multicolumn{8}{|l|}{ A-P linear, mm } \\
\hline Co-A boys & $83.36 \pm 4.18$ & 66.4 & 95.1 & $87.58 \pm 3.2$ & N/A & N/A & McNamara [13 \\
\hline $\mathrm{Co}-\mathrm{A}$ girls & $79.18 \pm 4.37$ & 63.2 & 92.4 & $84.73 \pm 2.7$ & N/A & N/A & McNamara $[13$ \\
\hline Co-Gn boys & $108.26 \pm 5.06$ & 87.8 & 122.1 & $110.95 \pm 4.3$ & N/A & N/A & McNamara [13 \\
\hline Co-Gn girls & $104.08 \pm 5.34$ & 84.5 & 119.2 & $109.39 \pm 5.0$ & N/A & N/A & McNamara $[13$ \\
\hline \multicolumn{8}{|l|}{ Vertical linear, mm } \\
\hline ANS-Me boys & $63.05 \pm 4.63$ & 50.6 & 74.2 & $61.46 \pm 3.9$ & N/A & N/A & McNamara [13 \\
\hline ANS-Me girls & $59.67 \pm 4.45$ & 49.7 & 72.8 & $60.35 \pm 4.9$ & N/A & N/A & McNamara [13 \\
\hline
\end{tabular}

uted to an increase in confidence of our finding that the relative dental protrusion of adolescent Kuwaitis is of clinical significance.

While the effective length of each jaw appears to be shorter in adolescent Kuwaitis when comparing with McNamara's [13] norms for the same age group (table 2), the difference in relative jaw length is clinically similar (table 1). The latter finding may be consistent with the fact that the adolescent Kuwaiti norms for relative prognathism are clinically similar to those of Riedel [7], McNamara [13], Downs [6], and Jacobson [12] (table 1). The clinically significant increase in profile convexity among adolescent Kuwaitis compared with the norm of Downs [6] may be explained by the tendency for reduced chin prominence in Kuwaitis, as well as to possible differences in vertical dimensions. The norm for the distance Pg-NB was originally proposed by Holdaway [9] but never formally published. We therefore used the figure suggested by Bell et al. [14] for clinical comparisons (table 1). However, we did use Holdaway's [9] proposed norm that the distances L1-NB and Pg-NB should be equal.

Adolescent Kuwaitis have a steeper mandibular plane when comparing with the norms of Downs [6] (table 1). While this finding may suggest a reduced potential for forward mandibular growth rotation and may be supported by the tendency for reduced chin prominence, it is not consistent with a y-axis angle close to the norms of Downs [6] (table 1). Our finding that the lower facial height of adolescent Kuwaitis is similar to McNamara's [13] ado- lescent norms despite the fact that the effective length of each jaw is smaller (table 2) may be interpreted as a relative increase in lower facial height, indirectly supporting a reduced potential for anterior growth rotation. However, in comparison to Riedel's [7] norm for angle MP/ $\mathrm{SN}$, adolescent Kuwaitis appear only to have a tendency for an increase in vertical dimensions, and the vertical relationships appear close to the norm of Björk and Skieller [1] for angle MP/PP (table 1).

Our findings are consistent with previous suggestions that Arab dentitions are more protrusive than according to the norms for Americans of European decent [24, 28]. The only exception in this respect is the U1-NA distance, which is similar to Steiner's [10] norm (table 1). One explanation may be that the tendency for a reduction in relative mandibular prognathism according to Riedel's [7] ANB angle in adolescent Kuwaitis (table 1) is associated with some compensatory retroclination of the maxillary incisors. This explanation may be supported by the fact that the increase in mandibular incisor inclination is considerably larger than that of the maxillary incisors when comparing with the common norms. The large increase in proclination and protrusion of the mandibular incisors in adolescent Kuwaitis relative to the published norms (table 1) suggests that a significantly larger proportion of adolescent Kuwaiti patients should be treated without extraction when using the present Kuwaiti norms as standards than indicated if comparing to the published norms. 
We confirm that the linear jaw dimensions differ between adolescent boys and girls [13], necessitating gender-specific norms regarding effective maxillary and mandibular length as well as lower anterior facial height for adolescent Kuwaitis (table 2). However, our findings do not suggest any gender differences in angular skeletal dimensions, relative jaw positions, or dentoalveolar dimensions at the time of early adolescence (table 1).

It should be stressed that our norms for incisor inclination and position only apply to adolescent Kuwaitis with skeletal relationships close to the normative values. Our findings show that Kuwaiti children have the potential for natural development of an almost ideal occlusion with inclination of the mandibular plane ranging from 18 to 55 degrees relative to the anterior cranial base, with a relative difference in prognathism of the anterior outline of the apical jaw bases ranging for negative 2 to more than 8 degrees, as well as with a profile ranging from straight to a convexity of about 20 degrees. Given the documented differences in dentoalveolar compensations concomitant with different directions of maxillomandibular translation during growth and development [1], incisor position and inclination are likely to be very different in subjects with skeletal morphology of either extreme. Accordingly, attempts should be made at exploring the need for establishing different dentoalveolar norms for different patterns of skeletal morphology.

Steiner's [10] acceptable compromises in position and inclination of the incisors call for adjustment of the inclination of the maxillary central incisor relative to the NA reference line and the inclination of the mandibular incisor relative to the NB reference line by 1 degree for every degree increase or decrease in ANB angle. However, our findings may be used to challenge this concept, since in our sample of adolescent Kuwaitis with natural development of almost ideal occlusion the ranges of angles U1/ $\mathrm{NA}$ and L1/NB were 21 and 34 degrees larger, respectively, than the range of angle ANB. Similarly, the variation of about 30 degrees in inclination of the mandibular incisors to the Frankfort Plane (table 1) among the subjects in our sample suggests that Tweed's [8] norm for mandibular incisor compensation to different skeletal deviations may be challenged.

Clinicians frequently recommend combined orthodontic and surgical treatment as the optimal option in patients with large skeletal discrepancies. However, our findings may be used to challenge that justification unless specific skeletal patterns are associated with impaired facial esthetics. Accordingly, attempts should be made at exploring how patients, parents, the laity, and members of the dental profession perceive the impact of differences in skeletal morphology on facial esthetics in subjects with favorable occlusal development.

\section{Conclusions}

The large increase in proclination and protrusion of the mandibular incisors in our representative sample of adolescent Kuwaitis with natural development of almost ideal occlusion suggests that a significantly larger proportion of adolescent Kuwaiti patients should be treated without extraction when using the present Kuwaiti norms relative to what may be indicated when compared to previously published norms. Our findings also indicate that the variation in skeletal relationships among subjects with satisfactory occlusal compensations is larger than previously documented, suggesting a need for establishing different norms for incisor inclination and protrusion for different skeletal patterns.

\section{Acknowledgment}

This research was supported by Kuwait University grant No. DD07/00. 


\section{References}

1 Björk A, Skieller V: Normal and abnormal growth of the mandible: a synthesis of longitudinal cephalometric implant studies over a period of 25 years. Eur J Orthod 1983;5:1-46.

$\checkmark 2$ Bishara SE, Peterson LC, Bishara EL: Changes in facial dimensions and relationship between the age of 5 and 25 years. Am J Orthod 1984; $85: 238-252$.

-3 Fidler BC, Årtun J, Joondeph DR, Little RM: Long-term stability of Angle Class II, Division 1 malocclusions with successful occlusal results at end of active treatment. Am J Orthod Dentofacial Orthop 1995; 107:276-285.

-4 Guyer EC, Ellis EE III, McNamara JA Jr, Behrens RG: Components of Class III malocclusion in juveniles and adolescents. Angle Orthod 1986;56:7-30.

$\checkmark 5$ Nanda SK: Patterns of vertical growth of the face. Am J Orthod Dentofacial Orthop 1988; 93:103-116.

-6 Downs WB: Variations in facial relations: their significance in treatment and prognosis. Am J Orthod 1948;34:812-840.

7 Riedel RA: The relation of maxillary structures to cranium in malocclusion and in normal occlusion. Angle Orthod 1952;22:142-145.

8 Tweed $\mathrm{CH}$ : The Frankfort-mandibular incisor angle (FMIA) in orthodontic diagnosis, treatment planning and prognosis. Angle Orthod 1954;24:121-169.

9 Holdaway RA: The relationship of the bony chin and the lower incisor to the line NB. Postgraduate course. University of California, 1955.

10 Steiner CC: Cephalometrics in clinical practice. Angle Orthod 1959;29:8-29.

$>11$ Ricketts RM: Foundation for cephalometric communication. Am J Orthod 1960;46:330 357.

12 Jacobson A: The 'Wits' appraisal of jaw disharmony. Am J Orthod 1975;67:125-138.

13 McNamara JA Jr: A method of cephalometric evaluation. Am J Orthod 1984;86:449-469.
14 Bell WH, Proffit WR, White RP: Surgical Correction of Dentofacial Deformities. Philadelphia, Saunders, 1980, vol 1, pp 137-150.

15 Björk A: The relationship of the jaws to the cranium; in Lundström A (ed): Introduction to Orthodontics. New York, McGraw-Hill, 1960 pp 104-140.

16 Cotton WN, Takano WS, Wong WMW: The Downs analysis applied to three other ethnic groups. Angle Orthod 1951;21:213-220.

17 Miura F, Inoue N, Suzuki K: Cephalometric standards for Japanese according to the Steiner analysis. Am J Orthod 1965;51:288-295.

18 Nanda R, Nanda RS: Cephalometric study of the dentofacial complex of North Indians. Am J Orthod 1969;39:22-28.

19 Garcia CJ: Cephalometric evaluation of Mexican Americans using the Downs and Steiner analyses. Am J Orthod 1975;68:67-74.

20 Iwasawa T, Moro T, Nakamura K: Tweed triangle and soft-tissue consideration of Japanese with normal occlusion and good facial profile. Am J Orthod 1977;72:119-127.

21 Hijighamidi M, Dougherty H, Garanki F: Cephalometric evaluation of Iranian children and its comparison with Tweed's and Steiner's standards. Am J Orthod 1981;79:192-197.

22 Cerci V, Soares Martins JE, de Oliveira Almeida MA: Cephalometric standards for white Brazilians. Int $\mathrm{J}$ Adult Orthod Orthognath Surg 1993;8:287-292.

23 Lew KKK: Cephalometric ideals in Chinese, Malay and Indian ethnic groups. Asian J Aesthet Dent 1994;2:35-38.

24 Hamdan AM, Rock WP: Cephalometric norms in an Arab population. J Orthod 2001;28:297300.

25 Davoody PR, Sassouni V: Dentofacial pattern differences between Iranians and American Caucasians. Am J Orthod 1978;73:667-675.
26 Shalhoub SY, Sarhan OA, Shaikh HS: Adult cephalometric norms for Saudi Arabians with a comparison of values for Saudi and North American Caucasians. Br J Orthod 1987;14: 273-279.

27 Kapila S: Selected cephalometric angular norms in Kikuyu children. Angle Orthod 1989; 59:139-144.

28 Bishara SE, Abdalla EM, Hoppens BJ: Cephalometric comparisons of dentofacial parameters between Egyptian and North American adolescents. Am J Orthod Dentofacial Orthop 1990;97:413-421.

29 Miyajima K, McNamara JA Jr, Kimura T, Murata S, Iizuka T: Craniofacial structure of Japanese and European-American adults with normal occlusions and well-balanced faces. Am J Orthod Dentofacial Orthop 1996;110: 431-438.

30 Wen-Jeng H, Taylor RW, Dasanayake AP: Determining cephalometric norms for Caucasians and African Americans in Birmingham. Angle Orthod 1998;68:503-512.

31 Alcade RE, Jinno T, Pogrel MA, Matsumura $\mathrm{T}$ : Cephalometric norms in Japanese adults. J Oral Maxillofac Surg 1998;56:129-134.

32 Ismael JS: Kuwait: Social Change in Historical Perspective, ed 1. New York, Syracuse University Press, 1982.

33 Royal Scottish Museum: The Evolving Culture of Kuwait. Edinburgh, Her Majesty's Stationary Office, 1985.

34 Loufty MS: Cephalometric evaluation of deep overbite and anterior open bite in Kuwait school children. Trans Eur Orthod Soc 1973: 281-285.

35 Dahlberg G: Statistical Methods for Medical and Biological Students. London, George Allen \& Unwin, 1940, pp 122-132.

36 Woodward M: Epidemiology: Study Design and Data Analysis, ed 2. New York, Chapman \& Hall/CRC, 2004, p 437.

37 Cochran WG: Sampling Techniques, ed 3. New York, Wiley, 1977. 